Revista

Ibero-Americana

de Estratégıa

\title{
RECURSOS ESTRATÉGICOS NO CENÁRIO 2009/2015 DAS IESS PARTICULARES DA REGIÃO NORDESTE DO BRASIL
}

\author{
STRATEGIC RESOURCES IN SCENARIO 2009/2015 OF PRIVATE HIGHER \\ EDUCATION INSTITUTIONS IN THE NORTHEAST REGION IN BRAZIL
}

\section{RECURSOS ESTRATÉGICOS EN EL ESCENARIO 2009/2015 DE LAS IESS PRIVADAS EN LA REGIÓN NORDESTE DE BRASIL}

\section{Jaime Romero de Sousa}

Mestre em Administração de Empresas pela Universidade de Fortaleza - UNIFOR

Diretor e Presidente da Faculdade Leão Sampaio

E-mail: jaimeromero@leaosampaio.edu.br (Brasil)

\section{Sérgio Henrique Arruda Cavalcante Forte}

Doutor em Administração de Empresas pela Fundação Getulio Vargas - FGV Professor da Universidade de Fortaleza - UNIFOR

E-mail: sergioforte@ unifor.br (Brasil)

\section{Oderlene Vieira de Oliveira}

Mestre em Administração de Empresas pela Universidade de Fortaleza - FATENE

Professora da pós-graduação da Faculdade de Tecnologia do Nordeste - UNIFOR

E-mail: oderlene@hotmail.com (Brasil) 
Recursos Estratégicos no Cenário 2009/2015 das IESS Particulares da Região Nordeste do Brasil

\title{
RECURSOS ESTRATÉGICOS NO CENÁRIO 2009/2015 DAS IESS PARTICULARES DA REGIÃO NORDESTE DO BRASIL
}

\section{RESUMO}

A expansão do número de Instituições de Ensino Superior (IES) no Brasil vem desacelerando desde 2005. Diante desta inflexão, objetiva-se identificar as dimensões de recursos estratégicos utilizadas pelas IESs privadas da Região Nordeste para um cenário mais provável de ocorrência no período 2009/2015. Para a identificação do cenário, utilizou-se o estudo de Porto e Régnier (2003) e como referencial de recursos competitivos, as dimensões dos estudos de Lynch e Baines (2004) e de Sousa et al. (2005). A metodologia foi descritiva e quantitativa, com aplicação de questionários. Os dados foram coletados no período de 2008/2009. Participaram da identificação e atualização do cenário 20 especialistas e 102 gestores. $\mathrm{Na}$ análise utilizaram-se técnicas descritiva, fatorial e clusters. Os resultados demonstram que o Cenário "Tudo pelo Mercado Adaptado" é o mais provável e que as IESs estão valorizando recursos que não proporcionam diferencial competitivo.

Palavras-chave: Cenário Prospectivo; Instituições de Ensino Superior; Recursos Estratégicos.

\section{STRATEGIC RESOURCES IN SCENARIO 2009/2015 OF PRIVATE HIGHER EDUCATION INSTITUTIONS IN THE NORTHEAST REGION IN BRAZIL}

\begin{abstract}
The number of Higher Education Institutions (HEI) in Brazil gives clear signs of deceleration. Considering this situation, it was decided to identify the strategic resource dimensions most likely used by Northeast Region private HEIs in Brazil in the scenario from 2009 to 2015 . The identification of scenario study developed by Porto and Régnier (2003) was used, as well as the dimensions described in Lynch and Baines (2004); Sousa et al. (2005) studies. The methodology used was a descriptive and quantitative type, performed by questionnaires. Field data were collected in the period 2008/2009. 20 experts and 102 managers participated in this study. Descriptive techniques, factor analysis, and cluster analysis was used in the data analysis process. The results showed that "All the Market Adapted Scenario" is the most likely and the HEIs of Northeast Region are considering resources that do not provide a competitive advantage.
\end{abstract}

Keywords: Prospective Scenario; Higher Education Institutions; Strategic Resources.

Revista Ibero-Americana de Estratégia - RIAE, São Paulo, v. 11, n. 2, p. 91-119, mai./ago. 2012. 
Jaime Romero de Sousa, Sérgio Henrique Arruda Cavalcante Forte \& Oderlene Vieira de Oliveira

RECURSOS ESTRATÉGICOS EN EL ESCENARIO 2009/2015 DE LAS IESS PRIVADAS

EN LA REGIÓN NORDESTE DE BRASIL

\section{RESUMEN}

La expansión del número de Instituciones de Educación Superior (IES) en Brasil se ha desecelerado desde 2005. Antes de esta inflexión, el objetivo fue identificar las dimensiones de los recursos estratégicos utilizados por instituciones particulares de educación superior en el Noreste para un escenario de más probable que ocurra en el período 2009/2015. Para la identificación de el scenario fue utilizado el estudio de Porto y Régnier (2003) y como un recurso de referencia en la competencia, los estudios de Lynch y Baines (2004) y Sousa et al. (2005). La metodología fue descriptiva y cuantitativa, con la aplicación de los cuestionarios. Los datos fueron recolectados en el período 2008/2009. Participó en la identificación y actualización de el escenario 20 especialistas y 102 directivos. Las técnicas de análisis utilizadas fueron descriptivos, factores y agrupaciones. Los resultados muestran que el escenario de "todo el mercado Adaptado" es más probable y que las instituciones de educación superior estan dando atención a los recursos que no proporcionan una ventaja competitiva.

Palabras-clave: Visión Prospectiva; Instituciones de Educación Superior; Recursos Estratégicos. 
Recursos Estratégicos no Cenário 2009/2015 das IESS Particulares da Região Nordeste do Brasil

\section{INTRODUÇÃO}

A conjuntura atual do ensino superior na América Latina tem evidenciado o surgimento de novos atores e a proliferação de instituições das mais variadas, compondo quadro bastante heterogêneo.

Segundo dados da Organização para a Cooperação e o Desenvolvimento Econômico (OCDE, 2008), o México atingiu índice de 15\% da população, a Argentina 14\% e o Chile, 13\%. O Brasil tem apenas $8 \%$ de sua população com ensino superior completo, enquanto a média dos países da OCDE é de 26\%. Se o Brasil conseguir ampliar esse índice em uma média de $0,5 \%$ ao ano, terá em dez anos chegado perto dos $15 \%$, considerado padrão para alguns países desenvolvidos.

No Brasil, observa-se uma evolução no número de Instituições de Ensino Superior (IESs) e de alunos matriculados. Dados do MEC/INEP (2008) apontam que no período pós- Lei de Diretrizes e Bases da Educação Nacional (LDB), de 1997 a 2006, houve uma variação de 152\% no total de IESs (de 900 em 1997, para 2.270 em 2006) e de 140\% no total de alunos matriculados (de 1.945.615 em 1997, para 4.676.646 em 2006). Neste período, o Ensino Superior Privado apresentou um acréscimo no número de IES de $193 \%$ e uma variação de $192 \%$ no número de alunos matriculados (1.186.433, em 1997 para 3.467.324, em 2006).

Na região Nordeste do Brasil, ressalta-se a evolução com maior intensidade, o que sinaliza crescimento maior dessa região em relação à média nacional. Este incremento também é sustentado principalmente pela evolução do setor privado, que passou de 58, em 1997, para 349 IESs em 2006 (variação de 502\%), e de 91.029, em 1997, para 439.862, em 2006, em alunos matriculados (variação de 383\%) (MEC/INEP, 2008).

Contudo, após uma rápida expansão vivida no período de 1997 a 2005, os números dão claros sinais de desaceleração de ritmo de crescimento. Já entre 2005 e 2006, o crescimento anual das IESs foi de apenas 5\%, saindo do patamar anterior de 14,8\% apresentado no início da década. Outro dado relevante, demonstra que em 2006 foram ofertadas 2.629 .598 vagas, mas apenas 1.448.509 foram preenchidas, resultando numa ociosidade de 45\% (MEC/INEP, 2008).

O mesmo fenômeno também é evidenciado na Educação Superior Privada da região Nordeste, que apresentava, em 1997, uma relação média de 1.569 alunos por IES. Contudo, em 2006, após um crescimento desproporcional do número de Instituições em relação ao crescimento do número de alunos, apresentou uma relação 19,7\% inferior, totalizando 1.260 alunos por IES particular e dando sinais claros da hipercompetitividade do setor na região (MEC/INEP, 2008; Nogueira, 2005).

Revista Ibero-Americana de Estratégia - RIAE, São Paulo, v. 11, n. 2, p. 91-119, mai./ago. 2012. 
Diante deste contexto, visando compreender a dinâmica desse universo empresarial de grande importância para o desenvolvimento social, econômico e cultural, escolheu-se a região Nordeste como foco deste trabalho. Definiu-se como proposta a identificação e atualização de um cenário prospectivo para o período de 2009 a 2015, entre os cenários prospectados por Porto e Régnier, que compreende o final do Governo Lula e mais cinco anos, com o mandato do próximo presidente e mais um ano de transição.

Assim, a questão que orientou o trabalho foi: quais as dimensões e recursos competitivos de utilização mais prováveis pelas IESs particulares do Nordeste frente ao cenário prospectado para o período de 2009 a 2015? Para tanto, definiu-se como objetivo geral identificar as dimensões de recursos competitivos de utilização mais prováveis pelas IESs particulares do Nordeste frente ao cenário prospectado.

Para o alcance do objetivo geral foram definidos os seguintes objetivos específicos: (1) Identificar e atualizar cenário prospectivo mais provável tendo como base quatro cenários prospectados por Porto e Régnier (2003), com o auxílio de expertises de diversas regiões do Brasil, atualizado com informações do Ministério da Educação e leituras de fontes especializadas; (2) Verificar a existência de inter-relações nas dimensões dos recursos; (3) Identificar fatores por dimensão de recursos.

Diante da importância do ensino superior para o desenvolvimento do país e da diminuição e do possível fortalecimento do número de atores (IESs), este trabalho reveste-se como de interesse tanto aos gestores quanto aos educadores brasileiros.

Este trabalho está estruturado com o objeto do estudo nesta introdução, seguido do referencial teórico (cenários prospectivos e recursos estratégicos da Resource Based View), metodologia, análise, conclusão e referências.

\section{CENÁRIOS PROSPECTIVOS}

Esses cenários compelem os gestores a começarem a pensar no futuro, considerando o que poderia ser (futuro), não o que foi (passado) (Wack, 1985). Eles possibilitam explorar diferentes padrões de negócio futuro, baseados em uma procura criativa (Godet, 1985). Para Schoemaker (1991, 1995), a maioria dos indivíduos e organizações tem uma tendência a subestimar seu desconhecimento sobre o futuro ou mesmo superestimar o futuro.

Os gestores têm por finalidade, quando tencionam mapear cenários, compreender as razões das mudanças dos "níveis do mar econômico" em que está inserido seu negócio, bem como incorporar tais variações às suas ações estratégicas (Ghemawat, 2007).

Revista Ibero-Americana de Estratégia - RIAE, São Paulo, v. 11, n. 2, p. 91-119, mai./ago. 2012. 
Recursos Estratégicos no Cenário 2009/2015 das IESS Particulares da Região Nordeste do Brasil

Cenários não são predições sobre o que irá acontecer, mas descrições, com base em hipóteses plausíveis, do que poderá acontecer (Oliveira, 2008). Permitem se tomar decisões estratégicas que sejam plausíveis para todos os futuros possíveis (Marcial e Grumbach, 2002). Não importa qual futuro aconteça, se tem maior chance de estar pronto para ele e influenciá-lo, tal perspectiva possibilita a análise de cenários (Schwartz, 2006).

Observa-se um crescimento em pesquisas acadêmicas sobre o tema "cenário" no Brasil, cabendo destaque as realizadas por Kato (2005), Moritz (2004), Santos (2004), Silva (2005), e Oliveira (2008). Com abordagem em "cenários", e "recursos", de forma conjunta, como é o caso desta pesquisa, encontrou-se somente o trabalho realizado por Oliveira (2008).

Porto e Régnier (2003) realizaram estudo com uma abordagem exploratória em que objetivaram mapear futuros possíveis e prováveis para o ensino superior no mundo, com ênfase no Brasil.

O estudo foi concluído com o desenho de quatro cenários, em um horizonte de 22 anos (2003 à 2025, estudo de Porto e Régnier, 2003), sendo eles:

\subsection{CENÁRIO A}

Educação como um bem público em um contexto de crescimento sustentado com orientação endógena - Conhecido por educação massificada, o Cenário A é de ampla inclusão social. Nesta perspectiva, a educação é assumida como o principal vetor de promoção da inclusão e da mobilidade ascendente, além de ser o grande capital dos países, especialmente em um contexto onde predomina a economia baseada no conhecimento.

\subsection{CENÁRIO B}

Educação como mercadoria num contexto de crescimento sustentado e abertura econômica - Também conhecido por massificação segmentada. Neste cenário, se busca a inclusão social pela via da educação, mas o ensino superior, antes de ser um bem público a ser provido e regulado pelo Estado, assume posição de produto a ser negociado segundo a lógica do mercado. Neste âmbito, o segmento privado responde por $80 \%$ das matrículas.

Revista Ibero-Americana de Estratégia - RIAE, São Paulo, v. 11, n. 2, p. 91-119, mai./ago. 2012. 


\subsection{CENÁRIO C}

Educação como bem público em um contexto de crescimento econômico instável e nãosustentado - Conhecido por massificação desqualificada, o Cenário C busca a inclusão social em que a educação não só é um bem público, como também é considerada um recurso estratégico para o país; mas o contexto nacional é de baixo crescimento econômico, com escassez de recursos públicos e modesto investimento privado, inclusive no ensino superior. De qualquer forma, com isso têm-se um maior equilíbrio na oferta, com o segmento público superando os $50 \%$ do atendimento da demanda.

\subsection{CENÁRIO D}

Educação como mercadoria em um contexto de crescimento econômico instável e nãosustentado - Também conhecido por tudo pelo mercado, o Cenário D, assim como nos demais, encontra-se presente como invariante a convicção cultural de que a educação atua como o principal mecanismo de mobilidade social ascendente e que por isso os indivíduos dos diversos estratos sociais encontram-se dispostos a investir na melhoria de seus patamares educativos. Nessa perspectiva, a concorrência é intensa e o mercado praticamente livre, com o vestibular praticamente eliminado nas IESs privadas.

\section{RECURSOS ESTRATÉGICOS}

As definições de estratégia conduzem à construção teórica de como as empresas podem alcançar performances superiores nos mercados em que elas atuam (Barney \& Arikan, 2006).

A teoria da Resource Based View (RBV) surgiu com o objetivo de desenvolver ferramentas para analisar a posição da empresa em relação aos recursos por ela utilizados e, a partir dessa apreciação, propor opções de estratégias a serem adotadas (Wernerfelt, 1984; Mintzberg et al., 2000; Hoopes, Madsen \& Walker, 2003).

A RBV, diferentemente da visão determinista da Organização Industrial, enfatiza o uso dos recursos internos na empresa como os principais determinantes de sua competitividade (Prahalad \& Hamel, 1990 e Wernerfelt, 1984). Há neste caso, um contraponto na análise de que o ambiente externo é considerado o principal determinante desde processo de concorrência.

Revista Ibero-Americana de Estratégia - RIAE, São Paulo, v. 11, n. 2, p. 91-119, mai./ago. 2012. 
Recursos Estratégicos no Cenário 2009/2015 das IESS Particulares da Região Nordeste do Brasil

As utilidades da RBV se multiplicaram e, após maior desenvolvimento, a teoria dos recursos não apenas se tornou base para criação de vantagem competitiva (Barney, 1991 e Grant, 1991), como também geração de barreiras a novos entrantes ou imitadores (Wernerfelt, 1984; Barney, 1991 e Grant, 1991).

Lynch e Baines (2004) realizaram um censo no Reino Unido, dedicando às IESs um estudo embasado em dados primários de pesquisas longitudinais. A primeira análise a ser destacada é que na performance superior de uma IES pudesse priorizar a exploração de recursos competitivos superiores, como, por exemplo, a qualidade de melhores estudantes; equipe administrativa; melhor qualidade no staff; qualidade no ensino e a habilidade de pesquisa para desenvolvimento de conhecimento.

Em âmbito nacional, Sousa et al. (2005) realizaram uma pesquisa do tipo survey com 100 diretores e coordenadores de instituições de ensino superior com o objetivo de identificar e categorizar os recursos competitivos das IESs particulares. Os resultados encontrados demonstraram que há uma compreensão dos recursos tangíveis e dos intangíveis como capazes de promover vantagens competitivas para uma Instituição de Ensino Superior privada, com ênfase principal na capacidade dinâmica para gestão destes recursos.

\section{METODOLOGIA DA PESQUISA}

Com base em Vergara (2000), quanto aos fins esta pesquisa caracteriza-se como descritiva, posto que identifica recursos em um cenário mais provável sem investigar a relação de causa e dependência entre eles. Quanto à natureza, classifica-se como quantitativa, fazendo-se uso de técnicas descritivas e multivariadas (Malhotra, 2006).

Após a elaboração do questionário para construção do cenário mais provável foi efetuado um pré-teste (Lakatos \& Marconi, 2005) no período de setembro a outubro de 2008, com a seleção intencional de quatro especialistas que faziam parte do grupo dos 30 previamente escolhidos.

O questionário sobre cenários foi aplicado para dois grupos distintos: sendo um grupo de 19 gestores de uma IES de porte médio, e outro formado por 30 especialistas de diversas IESs. A aplicação do instrumento para um grupo de uma Instituição, com a mediação de um consultor especializado em construção de cenários para o setor de Ensino Superior, objetivou obter a indicação do cenário mais provável. Após preenchimento dos questionários, foi feita a tabulação dos dados e o cenário D identificado pela maior frequência (48\%), seguido do cenário B com 25\%, numa escala de 0 a $100 \%$.

Revista Ibero-Americana de Estratégia - RIAE, São Paulo, v. 11, n. 2, p. 91-119, mai./ago. 2012. 
De posse do cenário mais provável (cenário D), desenvolveu-se um debate visando calibrálo com itens muito bem pontuados dos outros cenários e sugestões dos participantes.

O segundo grupo foi formado por 30 especialistas em cargos estratégicos de IESs de todo Brasil. Ressalta-se que o número de especialistas para escolha dos cenários foi definido com base em Godet (2000, p.71), que recomenda que o número de peritos em elaboração de cenários situe-se, frequentemente, entre 10 e 20.

Para a indicação dos especialistas, foi possível contar com o auxílio de uma empresa de Consultoria Educacional (Brasília/DF). Tendo em vista o estudo estar focado na região Nordeste e considerando as contribuições das diversas regiões do país, procedeu-se à seguinte distribuição: Região Nordeste: 20 especialistas - área de foco do estudo; Região Sudeste: 4 especialistas; Região Norte: 2 especialistas; Região Centro-Oeste: 2 especialistas; e Região Sul: 2 especialistas. Solicitouse que os 30 especialistas indicassem a probabilidade de ocorrência dos quatro cenários, numa escala de 0 a $100 \%$. O questionário foi enviado inicialmente via e-mail, como anexo, com cartaconvite. Tomou-se a iniciativa de disponibilizar o instrumento em uma home page, cujo acesso se deu por meio de um link. Obteve-se 20 questionários de retorno.

Para selecionar o cenário mais provável, utilizou-se a técnica de média aritmética das probabilidades de ocorrência. Também se utilizou da contagem por peritos dos cenários apontados como mais prováveis, Dos 20 peritos, 9 escolheram o cenário D e 5 o cenário C. O Cenário D obteve um percentual de $49 \%$, contra $25 \%$ do cenário C.

Com base no cenário escolhido e nas contribuições dos envolvidos nas fases de pré-teste, e na coleta de dados para os dois grupos (coordenadores de uma IES e especialistas de diversas IESs), procedeu-se à construção do cenário prospectado atualizado a ser utilizado como referência para a próxima etapa da pesquisa.

A segunda etapa compreendeu o período de dezembro de 2008 a fevereiro de 2009 com o objetivo de identificar os recursos competitivos de utilização provável pelas IESs particulares da região Nordeste do Brasil, frente ao cenário prospectado e atualizado na etapa anterior. Para tanto, foi aplicado um questionário aos principais gestores estratégicos das que constavam como contato no site do Ministério da Educação e Cultura (MEC), listando recursos em escala de 0 a 4 (likert) de grau de utilização, sendo 0 (não utilização), 1 (baixa utilização), 2 (moderada utilização), 3 (boa utilização), e 4 (forte utilização). O instrumento foi disponibilizado em uma home page. Para garantir o retorno dos questionários, optou-se pela não identificação das IESs e dos respondentes.

Em razão da carência de estudos específicos para o Ensino Superior Particular, especialmente na região Nordeste do Brasil, decidiu-se pelo censo com as 386 instituições (Mec,

Revista Ibero-Americana de Estratégia - RIAE, São Paulo, v. 11, n. 2, p. 91-119, mai./ago. 2012. 
Recursos Estratégicos no Cenário 2009/2015 das IESS Particulares da Região Nordeste do Brasil

2008). Para a seleção inicial dos recursos competitivos, utilizou-se como referência a pesquisa realizada por Lynch e Baines (2004), que se baseia em cinco dimensões: reputação, arquitetura organizacional, capacidade inovadora, competências essenciais e vantagem baseada em conhecimento. Essas dimensões foram ampliadas para sete em razão de levantamentos das regulamentações do Mec e Inep, de acordo com a realidade brasileira. Esse levantamento gerou a necessidade de coleta de dados com base em 39 recursos, distribuídos nas sete dimensões. Para uma análise estatística mais aprofundada, demandaria, no mínimo, 195 respondentes, ou seja, necessitaria de quase $50 \%$ de retorno dos questionários enviados, o que seria impraticável neste tipo de pesquisa, tendo em vista as dificuldades identificadas para obter a participação de grande número de gestores. As sete dimensões dos recursos encontram-se dispostas na figura 1.

Figura 1- Sete dimensões dos recursos.

\begin{tabular}{|c|c|c|}
\hline DIMENSÕES & \multicolumn{2}{|r|}{ RECURSOS } \\
\hline \multirow{7}{*}{ Reputação } & $\mathbf{R 1}$ & O processo de seleção de acadêmicos consegue atrair os melhores candidatos \\
\hline & $\mathbf{R 2}$ & Possui estruturas e tecnologias de promoção da comunicação institucional (interna e externa) \\
\hline & R3 & Desenvolve pesquisa de satisfação sobre a qualidade, preço dos cursos e serviços agregados \\
\hline & R4 & Possui projetos de fortalecimento da imagem institucional \\
\hline & $\mathbf{R 5}$ & $\begin{array}{l}\text { Adota programas e projetos de serviços comunitários nas áreas de conhecimento onde tem } \\
\text { excelência acadêmica }\end{array}$ \\
\hline & R6 & $\begin{array}{l}\text { Tem política de valorização dos acadêmicos que permite retê-los como futuros } \\
\text { colaboradores e ou parceiros }\end{array}$ \\
\hline & R7 & Adota um sistema de acompanhamento dos egressos \\
\hline \multirow{4}{*}{$\begin{array}{l}\text { Arquitetura } \\
\text { organizacional }\end{array}$} & $\mathbf{R 8}$ & $\begin{array}{l}\text { Realiza parceria com empresas e instituições visando à colocação dos alunos no mercado de } \\
\text { trabalho }\end{array}$ \\
\hline & R9 & Tem competência para levantar fundos ou desenvolver relações financeiras \\
\hline & $\mathbf{R} 10$ & $\begin{array}{l}\text { Desenvolve acordo e convênios com instituições parceiras em prol de estudantes e de } \\
\text { comunidades no entorno da IES }\end{array}$ \\
\hline & R11 & Possui programa de financiamento estudantil próprio ou em parceria (exceto FIES) \\
\hline
\end{tabular}

Revista Ibero-Americana de Estratégia - RIAE, São Paulo, v. 11, n. 2, p. 91-119, mai./ago. 2012. 
Jaime Romero de Sousa, Sérgio Henrique Arruda Cavalcante Forte \& Oderlene Vieira de Oliveira

\begin{tabular}{|c|c|c|}
\hline \multirow{4}{*}{$\begin{array}{l}\text { Capacidade de } \\
\text { inovação }\end{array}$} & $\mathbf{R 1 2}$ & $\begin{array}{l}\text { Possui programa de remuneração variável e ou benefícios extras, em razão do desempenho } \\
\text { da IES }\end{array}$ \\
\hline & $\mathbf{R 1 3}$ & Possui capacidade para desenvolver estratégias inovadoras nas áreas de atuação \\
\hline & $\mathbf{R 1 4}$ & Possui flexibilidade para se adaptar às inovações de mercado e do ambiente educacional \\
\hline & $\mathbf{R} 15$ & $\begin{array}{l}\text { Desenvolve e incentiva novas práticas e métodos de ensino que estimulem a presença e } \\
\text { participação dos alunos, gerando maior produtividade no processo ensino-aprendizagem }\end{array}$ \\
\hline \multirow{6}{*}{$\begin{array}{l}\text { Competências } \\
\text { essenciais }\end{array}$} & R16 & $\begin{array}{l}\text { Adota políticas de recrutamento, retenção e desenvolvimento de docentes, pesquisadores e } \\
\text { funcionários para seleção dos melhores profissionais }\end{array}$ \\
\hline & $\mathbf{R} 17$ & $\begin{array}{l}\text { Contempla a cultura voltada para a qualidade visando à melhoria contínua dos processos da } \\
\text { IES }\end{array}$ \\
\hline & $\mathbf{R 1 8}$ & $\begin{array}{l}\text { Detém tecnologias da informação em atendimento às necessidades da gestão do marketing, } \\
\text { acadêmica e financeira }\end{array}$ \\
\hline & $\mathbf{R 1 9}$ & $\begin{array}{l}\text { Desenvolve atividades extracurriculares que motivem e atraiam os alunos pata o ambiente } \\
\text { da IES. }\end{array}$ \\
\hline & $\mathbf{R 2 0}$ & Adota programas de estímulo à participação dos alunos no Enade. \\
\hline & $\mathbf{R} 21$ & Possui programa diferenciado de atendimento aos alunos e professores. \\
\hline \multirow{4}{*}{$\begin{array}{c}\text { Vantagem } \\
\text { baseada no } \\
\text { conhecimento }\end{array}$} & $\mathbf{R 2 2}$ & $\begin{array}{l}\text { Prepara os acadêmicos com a aplicação de teorias para resolução de problemas práticos ao } \\
\text { exercício profissional. }\end{array}$ \\
\hline & $\mathbf{R} 23$ & $\begin{array}{l}\text { Realiza cursos e treinamentos em diferentes áreas visando ao desenvolvimento de } \\
\text { conhecimentos e competências diferenciadas do corpo docente e demais recursos humanos. }\end{array}$ \\
\hline & $\mathbf{R 2 4}$ & $\begin{array}{l}\text { Valoriza a propriedade intelectual com pesquisa gerando: produção científica, publicações, } \\
\text { consultorias, patentes, materiais copyrigthed. }\end{array}$ \\
\hline & $\mathbf{R 2 5}$ & $\begin{array}{l}\text { Incentiva e oportuniza a construção de conhecimentos e tecnologias interdisciplinares entre } \\
\text { as diversas áreas e processos da IES. }\end{array}$ \\
\hline \multirow{2}{*}{ Infraestrutura } & $\mathbf{R} 26$ & Possui infraestrutura física como fator de vantagem competitiva. \\
\hline & $\mathbf{R} 27$ & Possui fatores diferenciados de conveniência (localização, áreas de convivência etc). \\
\hline
\end{tabular}

Revista Ibero-Americana de Estratégia - RIAE, São Paulo, v. 11, n. 2, p. 91-119, mai./ago. 2012. 
Recursos Estratégicos no Cenário 2009/2015 das IESS Particulares da Região Nordeste do Brasil

\begin{tabular}{|c|c|c|}
\hline & $\mathbf{R} 28$ & $\begin{array}{l}\text { Disponibiliza laboratórios de informática em quantidade que atenda a demanda acadêmica e } \\
\text { expectativa dos alunos. }\end{array}$ \\
\hline & $\mathbf{R} 29$ & $\begin{array}{l}\text { Garante acervo bibliográfico e outras fontes de pesquisa em atendimento à demanda } \\
\text { acadêmica e expectativa dos alunos. }\end{array}$ \\
\hline \multirow{10}{*}{ Gestão } & $\mathbf{R 3 0}$ & Adota processo decisório integrado entre IES e sua mantenedora. \\
\hline & $\mathbf{R 3 1}$ & Adota gestão profissional baseada em indicadores de desempenho. \\
\hline & $\mathbf{R 3 2}$ & Adota mecanismos de controle da evasão de alunos. \\
\hline & $\mathbf{R 3 3}$ & $\begin{array}{l}\text { Adota política de mensalidades diferenciadas por turno e cursos em decorrência da } \\
\text { demanda. }\end{array}$ \\
\hline & $\mathbf{R 3 4}$ & $\begin{array}{l}\text { Possui mecanismo contratual e política de cobrança que estimulam a redução da } \\
\text { inadimplência. }\end{array}$ \\
\hline & $\mathbf{R 3 5}$ & Possui gestão orçamentária e de custos por curso, aluno, turno e turmas. \\
\hline & $\mathbf{R 3 6}$ & $\begin{array}{l}\text { Utiliza sistema de autoavaliação institucional dos processos de ensino (professores), } \\
\text { aprendizagem (alunos) e gestão (gestores administrativos e de cursos). }\end{array}$ \\
\hline & R37 & $\begin{array}{l}\text { Os novos cursos, pesquisas e projetos de extensão são aprovados de acordo com a } \\
\text { compatibilidade entre os recursos, as capacidades institucionais e a demanda identificada. }\end{array}$ \\
\hline & $\mathbf{R 3 8}$ & $\begin{array}{l}\text { Adota ações que geram o envolvimento e a participação significativa do corpo docente nas } \\
\text { atividades de colegiado, extensão e complementares do curso }\end{array}$ \\
\hline & $\mathbf{R 3 9}$ & Possui ambiente de trabalho competitivo, porém harmonioso, integrado e participativo \\
\hline
\end{tabular}

Fonte: Elaborado pelos autores com base em Lynch e Baines (2004) e Sousa et al. (2005).

A escolha das técnicas de análise dos dados baseou-se nos objetivos da pesquisa, nas características dos dados e nas propriedades de técnicas estatísticas. (Malhotra, 2006). Inicialmente os dados coletados foram organizados no software Excel (versão 2007) e, posteriormente, transferidos para o SPSS (versão 16), sendo utilizadas as técnicas de análise de exploração de dados, clusters e fatorial.

A análise de clusters teve o propósito de reunir os respondentes segundo os recursos similares, ou seja, encontrar e separar objetos em grupos por características comuns. A análise 
fatorial foi utilizada com o intuito de verificar a inter-relação das variáveis dentro de cada dimensão, verificando se havia necessidade de uma subclassificação dentro dos grupos.

$\mathrm{Na}$ análise de clusters, o procedimento adotado foi o hierárquico aglomerativo do tipo Ward's method. A medida de distância usada foi a indicada para dados escalares/intervalares, ou seja, a "qui-quadrado". Cabe registrar, por fim, que foi verificado os pressupostos da análise de clusters, tais como amostra e multicolinearidade.

$\mathrm{Na}$ análise fatorial, o método de extração dos fatores utilizado foi o "Componente Principal" com rotação "Varimax". Os testes selecionados foram: KMO, Bartlett's test of sphericity, matriz anti-imagem e communalities.

\section{ANÁLISE DOS RESULTADOS}

\subsection{CENÁRIO PROSPECTADO}

$\mathrm{Na}$ atualização do cenário $\mathrm{D}$, levaram-se em conta, ainda, as regulamentações do MEC/INEP, tais como Lei de Diretrizes e Bases da Educação Nacional (LDB), Sistema Nacional de Avaliação da Educação Superior (Sinaes), Exame Nacional de Desempenho dos Estudantes (Enade), Fatores que compõem o Índice Geral de Cursos da Instituição de Educação Superior (IGC) e outros requisitos de regulação, supervisão e avaliação de instituições e cursos superiores. A descrição do cenário é apresentada na figura 2. Este cenário foi batizado com o nome de "Tudo pelo Mercado Regulamentado".

Figura 2- Descrição do cenário prospectado.

\section{Descrição do Cenário Prospectado (2009 a 2015)}

Neste cenário, encontra-se presente como invariante a convicção cultural de que a educação atua como o principal mecanismo de mobilidade social ascendente e, portanto, os indivíduos dos diversos estratos sociais encontram-se dispostos a investir na melhoria de seus patamares educativos. Este fato é reconhecido pelo Estado, mas a grande perspectiva assumida pelo poder público reside em priorizar a educação fundamental e média, visando não apenas a universalização, mas também a melhoria de qualidade e dos indicadores básicos, tais como índice de conclusão, redução da evasão e relação idade-série.

Revista Ibero-Americana de Estratégia - RIAE, São Paulo, v. 11, n. 2, p. 91-119, mai./ago. 2012. 
Recursos Estratégicos no Cenário 2009/2015 das IESS Particulares da Região Nordeste do Brasil

Neste contexto, apesar de iniciativas voltadas à ampliação do número de vagas nas Instituições Públicas (Federais, Estaduais, Cefets e Fatecs), a educação superior ou pós-média também será norteada por algumas metas e políticas, mas o principal agente executor do atendimento à demanda que cresce substancialmente continuará sendo a iniciativa privada.

O desequilíbrio entre a demanda e a oferta de mercado provocado pela crescente entrada de novas instituições privadas de ensino, fusões, aquisições, incorporações e abertura de capital, somados às também crescentes exigências do MEC, como o conceito atribuído pelo Enade, em razão do aproveitamento dos alunos, e a necessidade de maior titulação e qualificação do corpo docente, impõem desafios crescentes à gestão educacional. Outros fatores como altos índices de evasão e inadimplência, dificuldades na captação de novos alunos e pressão por aumento ou manutenção das margens operacionais trarão desafios ainda maiores aos gestores.

Nessa linha, a maioria das instituições privadas e particulares, para conseguir sobreviver em um ambiente econômico de incertezas e sem fontes de financiamento confiáveis ou de longo prazo priorizam a redução de custos, o que se traduz na operação com estruturas muito enxutas, baixas relações de docentes e funcionários por aluno, turmas bastante ampliadas, entre outras. Com isso, conseguem baixar seus preços, permitindo o ingresso de alunos das classes C e D nesse nível de ensino, mas com baixos padrões de qualidade e de eficácia muito heterogêneos.

A partir daí, opera-se um sistema de regulação, segundo o qual o poder público só intervém nos casos de flagrante desrespeito à lei ou não atendimento às regras emanadas pelo MEC. As instituições públicas ganham maior autonomia, mas algumas não conseguem se sustentar e poderão ser privatizadas. A oferta de ensino se amplia substancialmente, em parte alavancada por modernas tecnologias educacionais - entre elas o ensino a distância; e em parte pela variedade de alternativas, de todas as naturezas e preços. Nesta perspectiva, a concorrência é intensa e com o vestibular em processo de eliminação nas IESs privadas, o mercado tornou-se praticamente livre, O Enem e testes específicos redirecionam o ingresso dos estudantes no ensino superior.

Fonte: Pesquisa de campo (2009).

\subsection{ANÁlISE DOS RECURSOS COMPETITIVOS FRENTE AO CENÁRIO PROSPECTADO}

Exame gráfico dos dados - O recurso apontado na dimensão Reputação como o mais usual foi o R4, que possui projetos de fortalecimento da imagem institucional, com total de 307 pontos e o menos usual seria o recurso R7, que adota um sistema de acompanhamento dos egressos, com 178 pontos nesta dimensão. Na dimensão Arquitetura Organizacional, observou-se que o recurso R9, tem competência para levantar fundos ou desenvolver relações financeiras e foi apontado como o de maior utilização. Em relação ao recurso de menor utilização, o item R11 possui programa de financiamento estudantil próprio ou em parceria (exceto FIES) e apresentou a menor frequência de uso. Pode-se inferir que todos os recursos da dimensão Capacidade de Inovação tiveram boa indicação de uso, cabendo destacar o recurso R14, que possui flexibilidade para se adaptar às

Revista Ibero-Americana de Estratégia - RIAE, São Paulo, v. 11, n. 2, p. 91-119, mai./ago. 2012. 
inovações de mercado e do ambiente educacional, como o de maior indicação. Quanto a dimensão Competências Essências, os seis recursos que a compõem tiveram a maioria das respostas concentradas em boa utilização, ressaltando a importância dada a esses recursos pelos gestores das IES da região Nordeste.

Na dimensão vantagem baseada no conhecimento, os recursos mais utilizados são R22, que prepara os acadêmicos com aplicação de teorias para resolução de problemas práticos ao exercício profissional, e R23, que realiza cursos e treinamentos em diferentes áreas visando ao desenvolvimento de conhecimentos e competências diferenciadas do corpo docente e demais recursos humanos. As respostas tiveram uma grande concentração em "boa utilização", tendendo para "forte" em todas as estratégias listadas na dimensão infraestrutura. Os recursos R33, que adota política de mensalidades diferenciadas por turno e cursos em razão de demanda, e R34, que possui mecanismos contratual e política de cobrança que estimulam a redução da inadimplência, foram os apontados como sendo os mais usuais. Dentre os recursos, foi apontado como de menor utilização o R31, que adota gestão profissional baseada em indicadores de desempenho.

- Observações atípicas (outliers) - Analisando-se as observações atípicas presentes nos recursos identificou-se que tratavam de observações que se encontravam dentro dos intervalos da escala utilizada na metodologia. Assim, decidiu-se manter os outliers.

- Dados perdidos (missing values) - Buscando garantir que todos os itens do questionário fossem respondidos, disponibilizou-se o instrumento em uma home page (surveymonkey) que permite que se insira um comando que informa ao respondente no momento do envio se algum item estiver sem resposta, só possibilitando o envio quando todos estivessem preenchidos, ou seja, não houve dados perdidos.

- Alpha de Cronbach - Analisando-se as matrizes de correlação dos dados, observou-se consistência nas escalas indicando que são satisfatórias para aplicação da análise multivariada. A aplicação resultou nos coeficientes do Alfa de Cronbach não padronizado e padronizado para as variáveis das sete dimensões, obtendo-se coeficientes que variaram de 0,628 a 0,859 (Koning \& Franses, 2003).

Revista Ibero-Americana de Estratégia - RIAE, São Paulo, v. 11, n. 2, p. 91-119, mai./ago. 2012. 
Recursos Estratégicos no Cenário 2009/2015 das IESS Particulares da Região Nordeste do Brasil

\subsection{ANÁLISE DE CLUSTERS POR DIMENSÃO}

- Dimensão Reputação - Observando-se o dendrograma, optou-se pela divisão em cinco clusters. O cluster 1 agrupou $36 \%$ dos respondentes que apresentam, num contexto geral, o maior grau de utilização para todos os recursos desta dimensão. O cluster 2 agrupou $7 \%$ dos respondentes e possui como similaridade a "fraca utilização" do recurso R1, cujo processo de seleção de acadêmicos consegue atrair os melhores candidatos e "boa e forte utilização" do recurso R2, que possui estrutura e tecnologias de promoção da comunicação institucional interna e externa. O cluster 3 agrupou $30 \%$ dos respondentes que possui como similaridade a "baixa e moderada utilização" do recurso R7, que adota um sistema de acompanhamento dos egressos. Já o cluster 4 agrupou 19\% dos respondentes que não estão fazendo uso do recurso R7 que adota um sistema de acompanhamento dos egressos. Por fim, no cluster 5 foram agrupados $7 \%$ dos respondentes que apontaram a não-utilização do recurso R6, que tem política de valorização dos acadêmicos que permite retê-los como futuros colaboradores e ou parceiros.

- Dimensão Arquitetura Organizacional - Quanto ao número de grupos, a solução com três clusters mostrou-se a melhor, considerando-se o critério de tamanhos relativos (Malhotra, 2006). O cluster 1, que agrupou $36 \%$ dos respondentes que não utilizam o recurso R11, possui programa de financiamento estudantil próprio ou com parceria - exceto FIES. O cluster 2, que agrupou $45 \%$ dos respondentes que não usam o recurso R11, possui programa de financiamento estudantil próprio ou com parceria - exceto FIES, e tem grau de utilização moderado (2) ou bom (3) do recurso R9 - e competências para levantar fundos ou desenvolver relações financeiras. Já o cluster 3, que agrupou $19 \%$ dos respondentes que têm como similaridade a utilização do recurso R11, possui programa de financiamento estudantil próprio ou com parceria - exceto FIES.

- Dimensão Capacidade de Inovação - Quanto ao número de grupos, a solução com três clusters mostrou-se a melhor, considerando-se o critério de tamanhos relativos (Malhotra, 2006). O cluster 1, da dimensão capacidade de inovação, contou com $41 \%$ dos respondentes, que estão fazendo bom uso de todos recursos desta dimensão. Já o cluster 2, que contou com 39\% dos respondentes apresenta como similaridade "boa utilização" do recurso R15, que desenvolve e incentiva novas práticas e métodos de ensino que estimulem

Revista Ibero-Americana de Estratégia - RIAE, São Paulo, v. 11, n. 2, p. 91-119, mai./ago. 2012. 
a presença e participação dos alunos gerando maior produtividade no processo ensinoaprendizagem. No cluster 3, foram agrupados $20 \%$ dos respondentes que estão fazendo "baixo uso" do recurso R12, que possui programa de remuneração variável e ou benefícios extras em razão do desempenho da IES, e "boa utilização" do recurso R14, que confere flexibilidade para se adaptar às inovações de mercado e do ambiente educacional.

- Dimensão Competências Essenciais - Quanto ao número de grupos, a solução com três clusters mostrou-se a melhor. No cluster 1 , foram agrupados $40 \%$ dos respondentes que estão fazendo bom uso do recurso R17, que contempla a cultura voltada à qualidade visando a melhoria contínua dos processos da IES. Já o cluster 2 agrupou $40 \%$ dos respondentes que apontaram "boa e forte utilização" para o recurso R18, que detém tecnologias de informação em atendimento às necessidades da gestão do marketing, acadêmica e financeira. No cluster 3 , foram agrupados $20 \%$ dos respondentes, que apontaram não utilização do recurso R21, que possui programa diferenciado de atendimento aos alunos e professores.

- Dimensão vantagem baseada em conhecimento - Quanto ao número de grupos, a solução com dois clusters mostrou-se a melhor. O cluster 1 agrupou 60\% dos respondentes, que apresentaram boa utilização de todos os quatro recursos. Já o cluster 2 agrupou $40 \%$ dos respondentes com baixa ou nenhuma utilização para o recurso R24, que valoriza a propriedade intelectual com pesquisa gerando produção científica, publicações, consultorias, patentes e materiais copyrigthed.

- Dimensão infraestrutura - Quanto ao número de grupos, a solução com três clusters mostrou-se a melhor. O cluster 1 agrupou $47 \%$ dos respondentes com boa utilização para os quatro recursos. No cluster 2 agrupou $20 \%$ dos respondentes que apresentam a similaridade de forte utilização para os quatro recursos. Já o cluster 3 agrupou $33 \%$ dos respondentes com forte utilização do recurso R29, que garante acervo bibliográfico e outras fontes de pesquisa em atendimento à demanda acadêmica e expectativa dos alunos e boa utilização para os demais.

- Dimensão gestão - Quanto ao número de grupos, a solução com três clusters mostrou-se a melhor. O cluster 1 agrupou 54\% dos respondentes que informaram moderada utilização para os recursos R32, que adota mecanismos de controle da evasão de alunos, R33, que adota política de mensalidades diferenciadas por turno e cursos em razão da demanda, e

Revista Ibero-Americana de Estratégia - RIAE, São Paulo, v. 11, n. 2, p. 91-119, mai./ago. 2012. 
Recursos Estratégicos no Cenário 2009/2015 das IESS Particulares da Região Nordeste do Brasil

R34, que possui mecanismo contratual e política de cobrança que estimulam a redução da inadimplência. Já o cluster 2 agrupou $18 \%$ dos respondentes que apontaram fraca utilização para o recurso R32, que adota mecanismos de controle da evasão de alunos. No cluster 3 foram agrupados $28 \%$ dos respondentes que apontaram moderada ou nenhuma utilização para os recursos R30, que adota processo decisório integrado entre IES e mantenedora, e R31, que adota gestão profissional baseada em indicadores de desempenho.

Na Figura 3 se apresenta um resumo das médias dos grupos de cada dimensão. Observa-se que as IESs estão mais focadas na dimensão infraestrutura, confirmando a Hipótese 2 deste estudo, que aponta que os gestores valorizam fatores de conveniência e infraestrutura física.

Figura 3- Resumo das médias dos clusters das dimensões dos recursos .

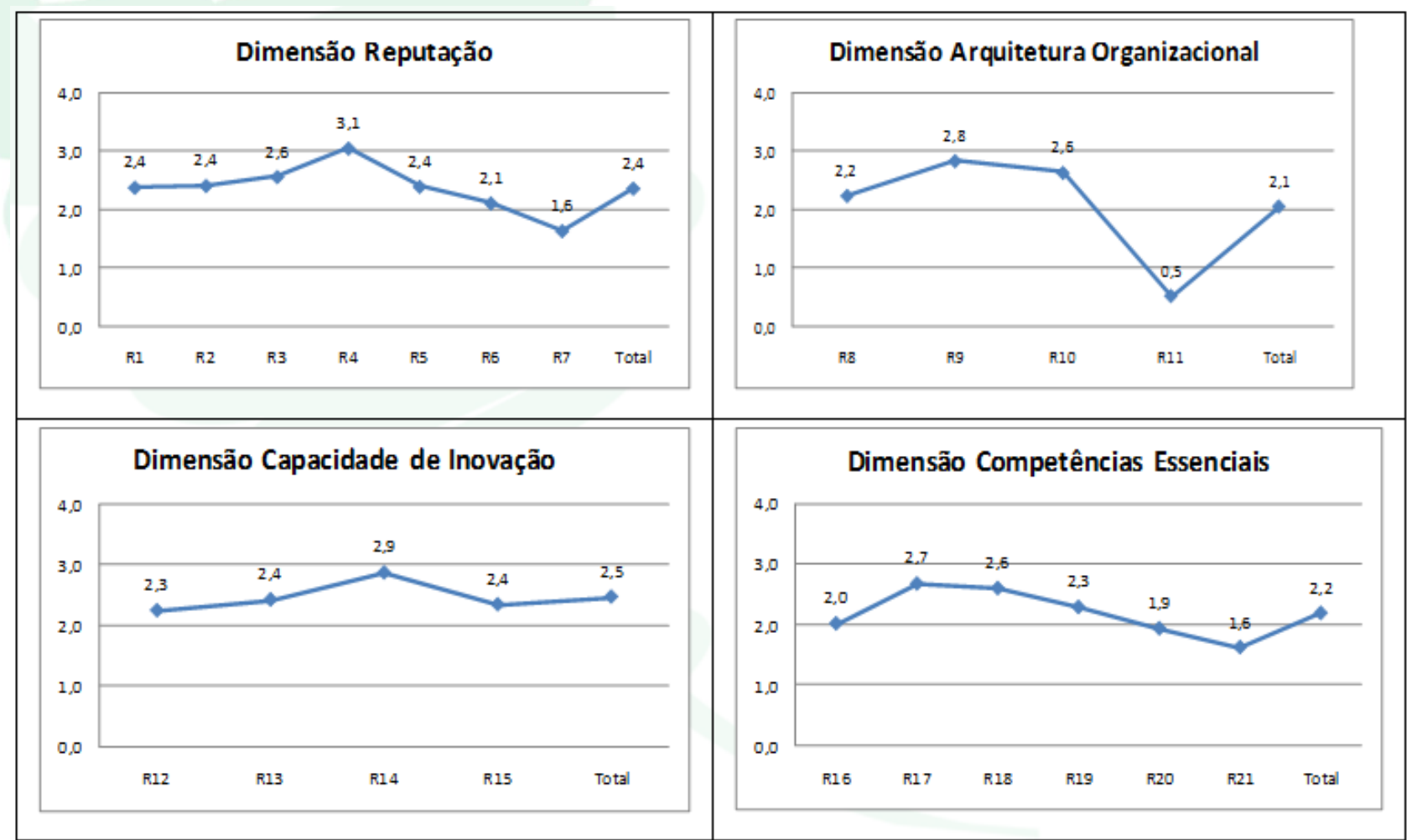

Revista Ibero-Americana de Estratégia - RIAE, São Paulo, v. 11, n. 2, p. 91-119, mai./ago. 2012. 
Jaime Romero de Sousa, Sérgio Henrique Arruda Cavalcante Forte \& Oderlene Vieira de Oliveira

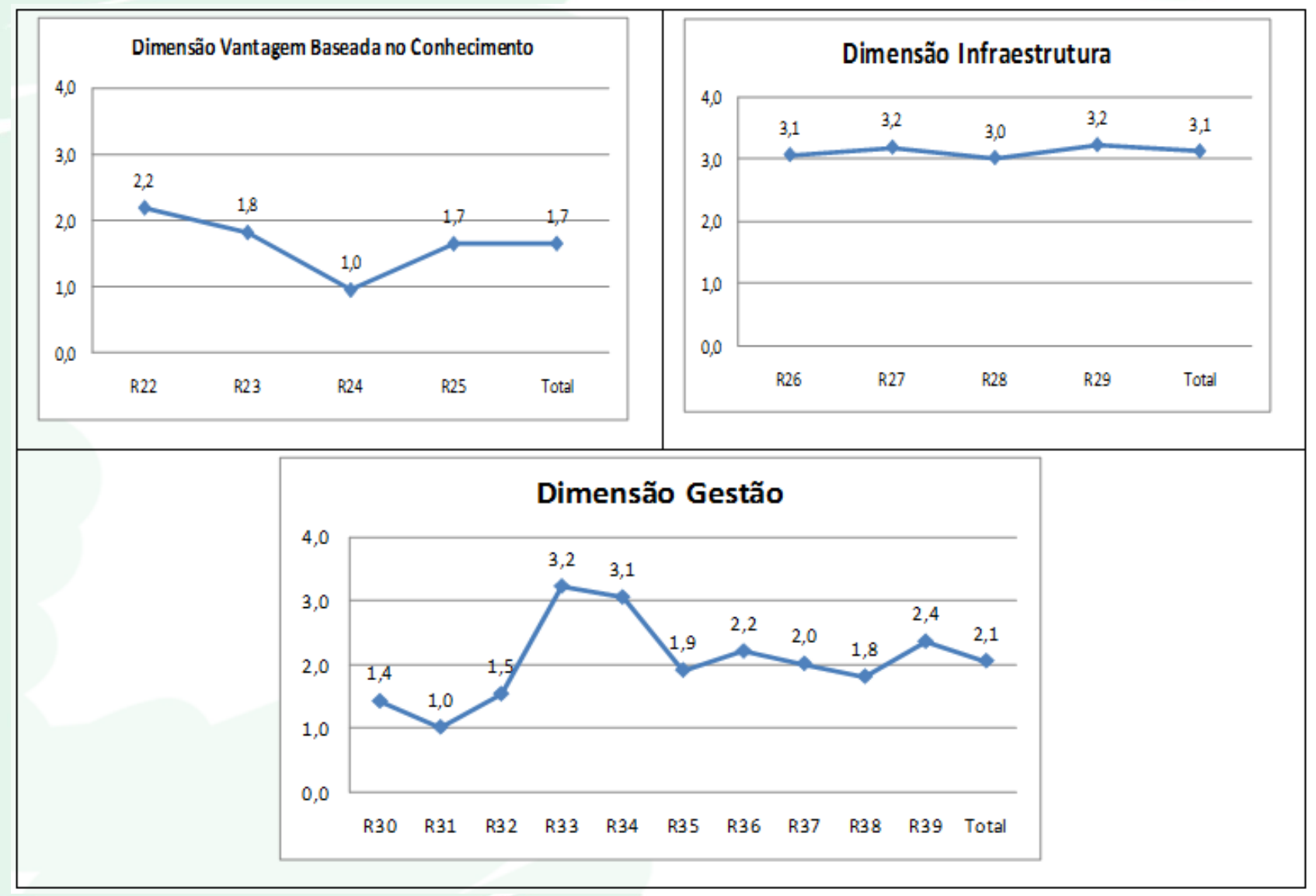

Fonte: Dados da pesquisa (2009).

Este posicionamento gera fragilidade na posição estratégica das organizações, uma vez que não são recursos para a geração de vantagem competitiva sustentável (Wenerfelt, 1984; Grant, 1991; Barney, 1995; Teece et al., 1997 e Barney \& Arikan, 2006), como também têm os menores pesos, conforme diretrizes e regulamentações do MEC.

Já a dimensão "Capacidade de Inovação", relacionada pelos gestores como uma das mais valorizadas (segunda no ranking), contrariou a Hipótese 3 que afirmava ser esta a de menor utilização. Este resultado demonstra que os gestores estão engajados num processo de melhoria e adaptação às mudanças frequentes do ambiente das IESs, contudo não devem ter foco concentrado em imitar práticas de outras instituições ou mesmo considerarem como inovação adquirir equipamentos ou outros recursos de fácil obtenção.

Considerando a dinamicidade do ambiente das IESs brasileiras (Andrade, 2006), a flexibilidade para se adaptar às inovações de mercado se caracteriza como item de grande relevância (recurso R14), contudo o maior desafio está em oferecer valor agregado e percebido pelo cliente (Barney, 1995 e Andrade, 2006).

A dimensão Reputação, avaliada como a mais importante na pesquisa de Sousa et al. (2005) e de importância destacada por Lynch e Baines (2004), aparece como a terceira de maior utilização, 
Recursos Estratégicos no Cenário 2009/2015 das IESS Particulares da Região Nordeste do Brasil

deixando claro que os gestores valorizam esta dimensão, mas estão prioritariamente focando que oportunidades. Na pesquisa, destacou-se o recurso R4, que possui projetos de fortalecimento da imagem institucional, como mais valorizado. Já o item de menor utilização R7, acompanhamento dos egressos, além de ser um dos itens valorizados nas avaliações do MEC, oferece, conforme estes mesmos autores, oportunidades de relacionamento e novos negócios.

A dimensão Competências Essenciais, quarta na classificação de utilização pelos gestores, teve o recurso R21, que possui programa diferenciado de atendimento aos alunos e professores, como sendo de menor valorização pelos gestores das IESs, causando certa preocupação, uma vez que a satisfação, tanto de alunos quanto professores, é relevante no reforço da imagem institucional, influenciando tanto na captação quanto na manutenção de alunos.

A dimensão Gestão, classificada na pesquisa entre as três de menor relevância, teve como recursos mais valorizados o R33, que adota política de mensalidades diferenciadas por turno e cursos em razão da demanda, e R34, que possui mecanismo contratual e política de cobrança que estimulam a redução da inadimplência, destacando a priorização por parte dos gestores de recursos de gestão voltados à sustentabilidade financeira em detrimento de recursos voltados ao atendimento de outras dimensões descritas no Sinaes (2004), como políticas de Pessoal do Corpo Docente e Corpo Técnico-Administrativo, Responsabilidade Social, Políticas para Ensino, Pesquisa, Pósgraduação e extensão, entre outras.

Entre os recursos de menor utilização apontou-se o R31, que adota a gestão profissional baseada em indicadores de desempenho, resultado este que contraria o estudo de Andrade (2006) que enfatiza a necessidade de maior profissionalização na gestão educacional, com tomada de decisão baseada nos indicadores de desempenho.

Já a dimensão Arquitetura Organizacional, que agrupa recursos voltados à formação de parcerias e convênios, teve como itens mais valorizados o R9, que tem competências para levantar fundos ou desenvolver relações financeiras, e R10, que desenvolve acordos e convênios com instituições parceiras em prol de estudantes e de comunidades no entorno da IES.

Para Sousa et al. (2005), o desenvolvimento de redes de relacionamento e alianças podem propiciar vantagem competitiva. Verifica-se neste estudo que as parcerias e convênios com essa finalidade obtiveram prioridade de utilização menor pelos gestores das IESs pesquisadas.

Já o recurso que apresentou a menor utilização foi o R11, que possui programa de financiamento estudantil próprio ou em parceria (exceto IES). É importante salientar que as classe C e D estão de forma crescente fazendo parte da demanda pelo Ensino Superior e que a criação de programa próprio ou em parceria para financiamento pode se caracterizar como um recurso valioso

Revista Ibero-Americana de Estratégia - RIAE, São Paulo, v. 11, n. 2, p. 91-119, mai./ago. 2012. 
(Barney,1995), competitivo ou estratégico, (Chaharbaghi e Lynch, 1999) em busca de maiores fatias de mercado ou mesmo contribuindo para o seu crescimento.

A dimensão vantagem baseada no conhecimento, destacada nos estudos de Lynch e Baines (2004) por proporcionarem um enriquecimento no ambiente acadêmico, motivação de professores e alunos e geração de novos conhecimentos e tecnologias, teve a menor classificação dentre as sete dimensões, com destaque para o recurso de menor utilização, o R24, que valoriza a propriedade intelectual com pesquisa gerando produção científica, publicações, consultorias, patentes, materiais copyrigthed.

\subsection{ANÁLISE FATORIAL DOS RECURSOS}

No teste KMO, todos os graus de explicação encontrados nas dimensões analisadas alcançaram valor superior a 0,5 , variando de 0,762 a 0,835 . Outro teste observado foi o de esfericidade de Bartlett. O teste indicou a possibilidade de aplicação da análise fatorial em todas as dimensões $($ Sig. $=0,000)$. Na opção Anti-imagem, em todas as dimensões, os valores da diagonal principal se mostraram superiores a 0,5, apontando bom poder de explicação dos fatores, ou seja, não sugeriu exclusão de nenhum recurso.

No teste communalities, observou-se que alguns recursos guardavam pouca relação com os fatores, obtendo explicações abaixo de 0,70 , mas como o intuito da utilização da análise fatorial não era de reduzir os recursos selecionados nos componentes para utilização dos fatores, então se procederam as análises, desconsiderando a sugestão de eliminação de alguns recursos.

Na figura 4, apresenta-se o resumo dos componentes extraídos dos recursos por dimensão. $\mathrm{Na}$ dimensão Reputação, foi dividida em dois fatores, sendo o primeiro rotulado como "De Resultado", que conta com um único recurso e o segundo, “de Esforço e Marketing”, com maior número de recursos e utilização.

Figura 4- Componentes das dimensões de recursos.

\begin{tabular}{|c|c|c|l|l|}
\hline \multirow{2}{*}{ DIMENSÃo } & COMPONENTE & \multicolumn{2}{|c|}{ RECURSOS } \\
\hline \multirow{2}{*}{ Reputação } & De resultado & $\mathbf{R 1}$ & $\begin{array}{l}\text { O processo de seleção de acadêmicos consegue atrair os melhores } \\
\text { candidatos. }\end{array}$ \\
\cline { 2 - 5 } & $\begin{array}{c}\text { De esforço e } \\
\text { marketing }\end{array}$ & $\mathbf{R 2}$ & Possui estruturas e tecnologias de promoção da comunicação institucional. \\
\hline
\end{tabular}

Revista Ibero-Americana de Estratégia - RIAE, São Paulo, v. 11, n. 2, p. 91-119, mai./ago. 2012. 


\begin{tabular}{|c|c|c|c|}
\hline & & $\mathbf{R 3}$ & $\begin{array}{l}\text { Desenvolve pesquisa de satisfação sobre a qualidade, preço dos cursos e } \\
\text { serviços agregados. }\end{array}$ \\
\hline & & $\mathbf{R 4}$ & Possui projetos de fortalecimento da imagem institucional. \\
\hline & & $\mathbf{R 5}$ & $\begin{array}{l}\text { Adota programas e projetos de serviços comunitários nas áreas de } \\
\text { conhecimento onde tem excelência acadêmica. }\end{array}$ \\
\hline & & R6 & $\begin{array}{l}\text { Tem política de valorização dos acadêmicos que permite retê-los como } \\
\text { futuros colaboradores e ou parceiros. }\end{array}$ \\
\hline & & $\mathbf{R 7}$ & Adota um sistema de acompanhamento dos egressos. \\
\hline \multirow{4}{*}{\multicolumn{2}{|c|}{ Arquitetura organizacional }} & $\mathbf{R 8}$ & $\begin{array}{l}\text { Realiza parceria com empresas e instituições visando à colocação dos } \\
\text { alunos no mercado de trabalho (estágio e emprego). }\end{array}$ \\
\hline & & $\mathbf{R 9}$ & $\begin{array}{l}\text { Tem competência para levantar fundos ou desenvolver relações } \\
\text { financeiras. }\end{array}$ \\
\hline & & $\mathbf{R} 10$ & $\begin{array}{l}\text { Desenvolve acordo e convênios com instituições parceiras em prol de } \\
\text { estudantes e de comunidades no entorno da IES. }\end{array}$ \\
\hline & & $\mathbf{R} 11$ & $\begin{array}{l}\text { Possui programa de financiamento estudantil próprio ou em parceira } \\
\text { (exceto FIES). }\end{array}$ \\
\hline \multirow{4}{*}{\multicolumn{2}{|c|}{ Capacidade de inovação }} & $\mathbf{R} 12$ & $\begin{array}{l}\text { Possui programa de remuneração variável e ou benefícios extras, em razão } \\
\text { do desempenho da IES. }\end{array}$ \\
\hline & & $\mathbf{R 1 3}$ & $\begin{array}{l}\text { Possui capacidade para desenvolver estratégias inovadoras nas áreas de } \\
\text { atuação. }\end{array}$ \\
\hline & & R14 & $\begin{array}{l}\text { Possui flexibilidade para se adaptar às inovações de mercado e do } \\
\text { ambiente educacional. }\end{array}$ \\
\hline & & $\mathbf{R} 15$ & $\begin{array}{l}\text { Desenvolve e incentiva novas práticas e métodos de ensino que estimulem } \\
\text { a presença e participação dos alunos gerando maior produtividade no } \\
\text { processo ensino-aprendizagem }\end{array}$ \\
\hline \multirow{3}{*}{$\begin{array}{l}\text { Competências } \\
\text { Essenciais }\end{array}$} & \multirow{3}{*}{$\begin{array}{l}\text { Políticas, } \\
\text { programas e } \\
\text { atitudes }\end{array}$} & R16 & $\begin{array}{l}\text { Adota políticas de recrutamento, retenção e desenvolvimento de docentes, } \\
\text { pesquisadores e funcionários para seleção dos melhores profissionais }\end{array}$ \\
\hline & & $\mathbf{R} 17$ & $\begin{array}{l}\text { Contempla a cultura voltada para a qualidade visando à melhoria contínua } \\
\text { dos processos da IES. }\end{array}$ \\
\hline & & R19 & $\begin{array}{l}\text { Desenvolve atividades extracurriculares que motivem e atraiam os alunos } \\
\text { para o ambiente da IES. }\end{array}$ \\
\hline
\end{tabular}

Revista Ibero-Americana de Estratégia - RIAE, São Paulo, v. 11, n. 2, p. 91-119, mai./ago. 2012. 


\begin{tabular}{|c|c|c|c|}
\hline & & $\mathbf{R} 20$ & Adota programas de estímulo à participação dos alunos no Enade. \\
\hline & & $\mathbf{R} 21$ & Possui programa diferenciado de atendimento aos alunos e professores. \\
\hline & $\begin{array}{l}\text { Tecnologia e } \\
\text { Informação }\end{array}$ & $\mathbf{R} 18$ & $\begin{array}{l}\text { Detém tecnologias da informação em atendimento às necessidades da } \\
\text { gestão do marketing, acadêmica e financeira. }\end{array}$ \\
\hline \multirow{4}{*}{\multicolumn{2}{|c|}{$\begin{array}{l}\text { Vantagem baseada no } \\
\text { conhecimento }\end{array}$}} & $\mathbf{R} 22$ & $\begin{array}{l}\text { Prepara os acadêmicos com a aplicação de teorias para resolução de } \\
\text { problemas práticos ao exercício profissional. }\end{array}$ \\
\hline & & $\mathbf{R 2 3}$ & $\begin{array}{l}\text { Realiza cursos e treinamentos em diferentes áreas visando ao } \\
\text { desenvolvimento de conhecimentos e competências diferenciadas do corpo } \\
\text { docente e demais recursos humanos. }\end{array}$ \\
\hline & & $\mathbf{R} 24$ & $\begin{array}{l}\text { Valoriza a propriedade intelectual com pesquisa gerando: produção } \\
\text { científica, publicações, consultorias, patentes, materiais copyrigthed. }\end{array}$ \\
\hline & & $\mathbf{R 2 5}$ & $\begin{array}{l}\text { Incentiva e oportuniza a construção de conhecimentos e tecnologias } \\
\text { interdisciplinares entre as diversas áreas e processos da IES. }\end{array}$ \\
\hline \multirow{4}{*}{\multicolumn{2}{|c|}{ Infraestrutura }} & $\mathbf{R} 26$ & Possui infraestrutura física como fator de vantagem competitiva. \\
\hline & & $\mathbf{R} 27$ & $\begin{array}{l}\text { Possui fatores diferenciados de conveniência (localização, estacionamento, } \\
\text { áreas de convivência etc). }\end{array}$ \\
\hline & & $\mathbf{R} 28$ & $\begin{array}{l}\text { Disponibiliza laboratórios de informática em quantidade que atenda a } \\
\text { demanda acadêmica e expectativa dos alunos. }\end{array}$ \\
\hline & & $\mathbf{R 2 9}$ & $\begin{array}{l}\text { Garante acervo bibliográfico e outras fontes de pesquisa em atendimento à } \\
\text { demanda acadêmica e expectativa dos alunos. }\end{array}$ \\
\hline \multirow{5}{*}{ Gestão } & \multirow{5}{*}{$\begin{array}{l}\text { Foco } \\
\text { (administrativo) }\end{array}$} & $\mathbf{R 3 0}$ & Adota processo decisório integrado entre a IES e sua mantenedora. \\
\hline & & $\mathbf{R 3 1}$ & Adota gestão profissional baseada em indicadores de desempenho. \\
\hline & & $\mathbf{R 3 5}$ & Possui gestão orçamentária e de custos por curso, aluno, turno e turmas. \\
\hline & & R36 & $\begin{array}{l}\text { Utiliza sistema de autoavaliação institucional dos processos de ensino } \\
\text { (professores), aprendizagem (alunos) e gestão (gestores administrativos e } \\
\text { de cursos). }\end{array}$ \\
\hline & & $\mathbf{R} 37$ & $\begin{array}{l}\text { Os novos cursos, pesquisas e projetos de extensão são aprovados de acordo } \\
\text { com a compatibilidade entre os recursos, capacidades institucionais e a } \\
\text { demanda identificada. }\end{array}$ \\
\hline
\end{tabular}

Revista Ibero-Americana de Estratégia - RIAE, São Paulo, v. 11, n. 2, p. 91-119, mai./ago. 2012. 
Recursos Estratégicos no Cenário 2009/2015 das IESS Particulares da Região Nordeste do Brasil

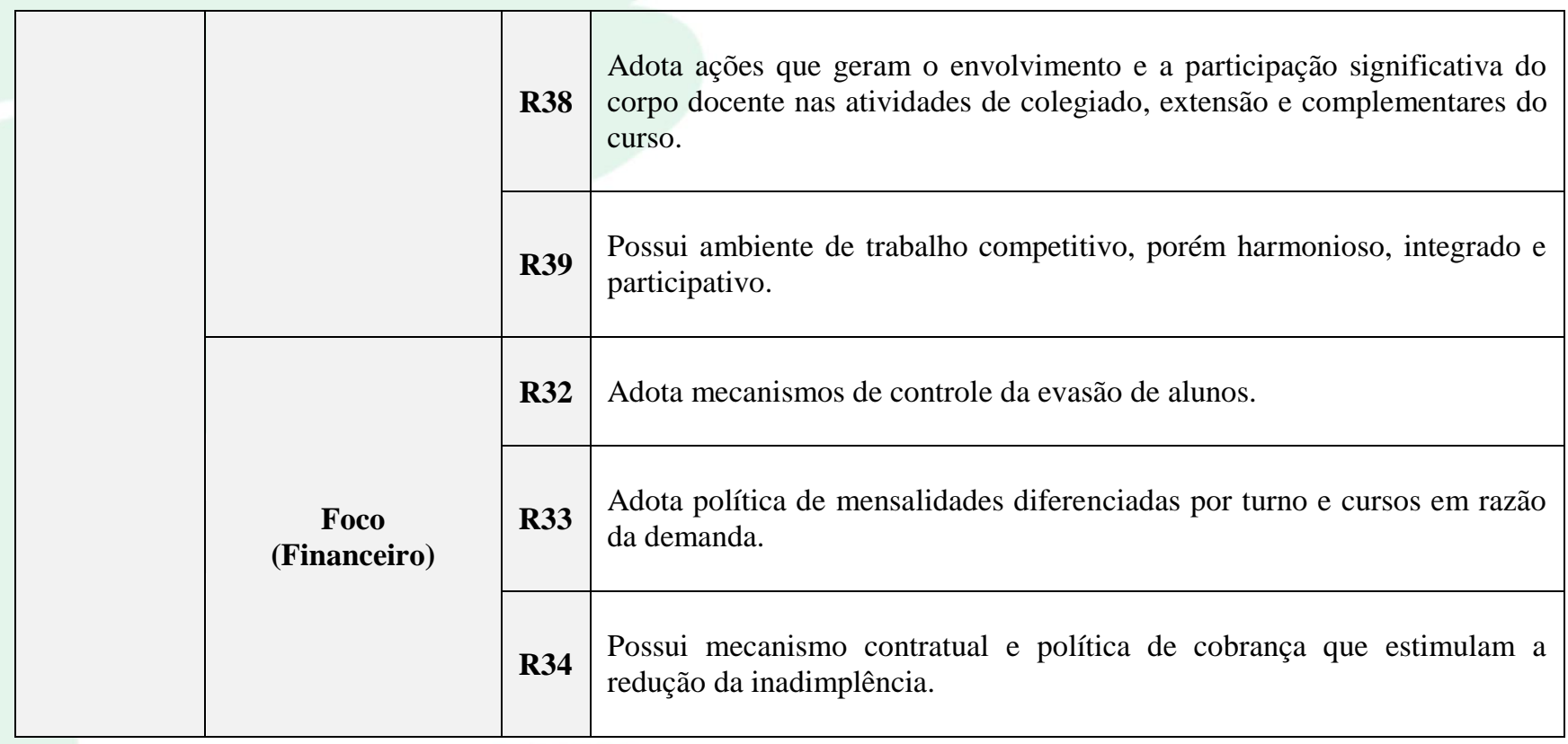

Fonte: Pesquisa de campo (2009).

Na dimensão arquitetura organizacional e capacidade de inovação, obteve-se um único fator dentro da dimensão. Na dimensão competências essenciais foram identificados dois fatores: "Políticas, Programas e Atitudes" e “Tecnologia e Informação", sendo este segundo formado por um único recurso. Na dimensão vantagem baseada no conhecimento e infraestrutura foi identificado um único fator em cada dimensão. $\mathrm{Na}$ dimensão gestão foram formados dois fatores: o primeiro, intitulado "Foco Administrativo", com recursos de utilização moderada, agrupa recursos que envolvem diretamente a gestão das IESs, e o segundo, rotulado como "Foco Financeiro", de maior utilização que estimula a redução da inadimplência, com visão mais focada na sustentabilidade financeira.

A análise fatorial empregada na divisão dos fatores em cada dimensão, além de apresentar a estrutura das inter-relações entre um grupo de variáveis, possibilita também, efetuar um resumo ou redução dos dados, facilitando novas análises e pesquisas.

\section{CONSIDERAÇÕES FINAIS}

O cenário construído é de concorrência intensa e de mercado praticamente livre, no qual a demanda continuará sendo atendida principalmente pelas instituições privadas, mesmo considerando as diversas iniciativas do governo federal visando à ampliação do número de vagas nas instituições públicas.

Revista Ibero-Americana de Estratégia - RIAE, São Paulo, v. 11, n. 2, p. 91-119, mai./ago. 2012. 
O cenário identificado como o mais provável foi o cenário D -Tudo pelo Mercado (subseção 2.4) adaptado (Figura 2), em razão de novas regras do MEC e da avaliação dos peritos. Dos recursos estratégicos, a dimensão infraestrutura foi a que mais foi evidenciada. De acordo com Lynch e Baines (2004), em alguns países desenvolvidos foi demonstrado que esta dimensão de recursos não é considerada como oportunidade de obtenção de diferencial competitivo sustentável, por não se tratarem de recursos diferenciados na geração de valor. O próprio MEC, ao avaliar as IES, pontua o quesito infraestrutura com o menor peso dentre os itens avaliados. Esta situação apresentada caracteriza certa fragilidade ao posicionamento estratégico das IESs da Região Nordeste, que por estarem numa arena bastante competitiva, não poderiam proporcionar facilidades (ou mesmo oportunidades) a concorrentes, sejam eles locais, regionais ou mesmo de outros países.

Já a dimensão capacidade de inovação foi identificada pelos gestores como uma das mais valorizadas (segunda no ranking). Este resultado demonstra que os gestores estão engajados num processo de melhoria e adaptação às mudanças frequentes do ambiente das IES, em concordância com as afirmações de Barney (2002), quanto à importância do uso da criatividade e atitude empreendedora, que englobam os conceitos de inovação, como parte da escolha de uma estratégia consistente. Os gestores precisam contudo estar alertas para o fácil acesso e barateamento das tecnologias, que podem descaracterizar recursos, principalmente os tangíveis, como geradores de diferencial competitivo.

Já a dimensão reputação, avaliada como a mais importante nas pesquisas de Sousa et al. (2006) e de importância destacada por diversos autores, inclusive Lynch e Baines (2004), aparece neste trabalho como a terceira de maior utilização, confirmando a necessidade, por parte dos gestores, de ampliarem a visão para os recursos intangíveis. As outras dimensões, de menor utilização, foram valorizadas na seguinte ordem decrescente: competências essenciais, gestão, arquitetura organizacional e vantagem baseada no conhecimento.

Em resumo, a pesquisa aponta a valorização de recursos considerados não geradores de vantagem competitiva sustentável. Uma outra contribuição foi identificar fatores no rol das dimensões, com relevância prática e de continuidade para próximas pesquisas.

Este estudo chama atenção para se interpretar o resultado da análise fatorial, considerandose a distribuição de frequência, uma vez que os fatores podem agrupar variáveis que estão interrelacionadas, mas de baixa ou nula frequência, nem sempre sugerindo que os primeiros fatores com maior correlação são os de maior utilização, como é caso desta pesquisa.

Como limitações apresentam-se a aplicação individual de questionários aos especialistas em diversas regiões, sabendo-se que a discussão em grupo seria a melhor opção, e ainda, a não 
Recursos Estratégicos no Cenário 2009/2015 das IESS Particulares da Região Nordeste do Brasil

identificação das IESs (tipo de IES, porte, estado), pois como se tratava de comportamentos estratégicos e na fase do pré-teste já havia se detectado que se teria dificuldades na coleta de dados, caso houvesse identificação, tomou-se essa decisão.

Em termos práticos, esta pesquisa contribui com os gestores das IESs particulares e até das IESs públicas para repensarem suas organizações competitivamente, principalmente nos chamados recursos intangíveis expostos no decorrer do trabalho (reputação, arquitetura organizacional, capacidade inovadora, competências essenciais e vantagem baseada no conhecimento). Na linha acadêmica, sugere-se continuar os estudos nas demais regiões do país, para se fazer uma análise comparativa. Outra sugestão é utilizar os fatores como redutores das estratégias e recursos e se fazer também uma análise independente das posturas e dimensões, podendo-se, então, formar novos fatores ou mesmo relacioná-los.

\section{REFERÊNCIAS}

Andrade, A. R. (2006). Planejamento estratégico: formulação, implementação e controle. Texto básico para o curso de graduação em Administração. Blumenau: Universidade Regional de Blumenau.

Barney, J. B. (1991). Gaining and sustaining firm resources and sustained competitive advantage. Journal of Management, 17(1), 99-120. Doi: 10.1177/014920639101700108

Barney, J. B. (1995). Looking inside for competitive advantage. Academy of Management Executive, v. 9.

Barney, J. B. (2002). Firm resources and sustained competitive advantage. (2ed.) New Jersey. Prentice Mall.

Barney, J. B., Arikan, A. (2001). The resource-based view: origins and implications. Handbook of Strategic Management, forthcoming.

Barney, J. B., Hesterly, W. S. (2007). Administração estratégica e vantagem competitiva. Tradução Mônica Rosemberg: revisão técnica Pedro Zanni. São Paulo: Pearson Prentice Hall.

Chaharbaghi, K., Lynch, R. (1999). Sustainable competitive advantage: towards a dynamic resource-based strategy. Management Decision, v. 37. Doi: 10.1108/00251749910252012

Revista Ibero-Americana de Estratégia - RIAE, São Paulo, v. 11, n. 2, p. 91-119, mai./ago. 2012. 
Ghemawat, P. (marc. 2007). Managing differences: the central challenge of global strategy. Harvard Business Review, 85(3),. 58-69.

Godet, M. (1985). Prospective et planification stratégique. Econômica: Paris.

Godet, M. (1993). Manual de prospectiva estratégica: da antecipação à ação. Lisboa: Dom Quixote.

Godet, M. (2000). A “Caixa de ferramentas" da prospectiva estratégica. Lisboa: Cepes. 97 p. (Caderno do Cepes n. 5).

Grant, R. M. (1991). The Resource-based theory of competitive advantage: implications for strategy formulation. California Management Review, 33(3), spring, 114-135.

Hamel, G., Prahalad, C. K. (1995). Competindo para o futuro: estratégias inovadoras para obter o controle do seu setor e criar mercados de amanhã. Rio de Janeiro: Campus.

Hoopes, D. G., Madsen, T. L., Walker, G. (2003). Guest editors' introduction to the special issue: why is there a Resource-Based View? Toward a theory of competitive heterogeneity. Strategic Management Journal, v. 24, 889-902. Doi: 10.1002/smj.356

Kato, J. M. (2005). Cenários estratégicos para a indústria de transportes rodoviários de cargas no Brasil. 167 f. Tese (Doutorado em Eng. Produção) - UFSC, Florianópolis.

Koning, A. J., Franses, P. H. (2003). Confidence intervals for Cronbach's coefficient alpha values. Research in Management. (n. 16).

Lakatos, E. M., Marconi, M. A. (2005). Fundamentos de metodologia científica. (6. ed.) São Paulo: Atlas.

Lynch, R., Baines, P. (July 2004). Strategy development in UK higher education: towards resourcebased competitive advantages. Journal of Higher Education Policy and Management,. 26(2).

Malhotra, N. K. (2006). Pesquisa de marketing: uma orientação aplicada. (4. ed.) Porto Alegre: Bookman.

Marcial, E. C., Grumbach, R. J. S. (2002). Cenários prospectivos: como construir um futuro melhor. (2. ed.) Rio de Janeiro: FGV.

MEC/INEP. (2008). Sinopses estatísticas da educação superior - Graduação. Recuperado em 20 set.2008, de: <http://www.inep.gov.br/superior/censosuperior/sinopse/>.

Revista Ibero-Americana de Estratégia - RIAE, São Paulo, v. 11, n. 2, p. 91-119, mai./ago. 2012. 
Mintzberg, H., Ahlstrand, B., Lampel, J. (2000). Safári de estratégia: um roteiro pela selva do planejamento estratégico. Porto Alegre: Bookman.

Moritz, G. O. (2004). Planejamento por cenários prospectivos: a construção de um referencial metodológico baseado em caso. Tese de Doutorado em Engenharia de Produção) - UFSC, Florianópolis.

Morsoleto, R. H. C. (2008). Educação Superior: um novo panorama. Recuperado em 9 set.2008, de: 〈http://kplus.cosmo.com.br/materia.asp?co=3\&rv=Vivencia>.

Nogueira, E. M. M. M. (2005). O ambiente competitivo das IES do Ceará à luz do modelo de D 'Aveni. Dissertação de Mestrado em Administração-UNIFOR, Fortaleza, Brasil.

OCDE.(2008) Organização para a Cooperação e o Desenvolvimento Econômico. O futuro da $\begin{array}{lllll}\text { educação.Recuperado } & \text { em } & 20 & \text { set.2008, de: }\end{array}$ http://revistaensinosuperior.uol.com.br/textos.asp?codigo=12124.

Oliveira, O. V. (2008). Indústria bancária brasileira: construindo cenários prospectivos $e$ identificando as estratégias e os recursos competitivos de utilização mais provável. $189 \mathrm{f}$. Dissertação de Mestrado em Administração de Empresas) - UNIFOR, Fortaleza, Brasil.

Porto, C. (2001). Macrocenários da Amazônia 1998 - 2020. Macroplan. Recuperado em 20 set.2008, de: < http://ftp.mct.gov.br/temas/meioambiente/news/Macroplan.PDF

Porto, C., Régnier, K. (2003). O ensino superior no mundo e no Brasil - Condicionantes, tendências e cenários para o horizonte 2003-2025: uma abordagem exploratória. Dez.

Santos, N. M. G. (2004). Um estudo prospectivo sobre a previdência social brasileira. Tese de Doutorado em Engenharia da Produção - UFRJ, Rio de Janeiro, Brasil.

Schoemaker, P.J. H. (1991). When and how to use scenario planning: a heuristic approach. Journal of Forecasting. 10(6), 549. Doi: 10.1002/for.3980100602

Schoemaker, P.J.H. (1995). Scenario planning: a tool for strategic thinking. Sloan Management Review,. 36(2), 25.

Schwartz, P. (2006). A arte da visão de longo prazo. (4. ed.) Rio de Janeiro: Best Seller.

Silva, I. P. (2005). Análise de cenários: teoria e aplicação para bancos de varejo no mercado brasileiro. Monografia de Bacharelado em Administração) - USP, São Paulo, Brasil.

Sinaes. (2008). Legislação e normas da educação superior. Portaria $\mathrm{n}^{\circ}$ 1.264. Recuperado em set.2008, de:<http://www.inep.gov.br>.

Revista Ibero-Americana de Estratégia - RIAE, São Paulo, v. 11, n. 2, p. 91-119, mai./ago. 2012. 
Sousa, J. L. R., Ferreira, F., Moura, S. (2005). Proposta de categorização dos recursos estratégicos de IES particular: uma contribuição com base nos modelos da VBR e da hipercompetição. In: ENANPAD, 29, Brasília. Anais... Brasília. ANAPAD. 1 CD-ROM.

Teece, D.J. et al. (August 1997). Dynamic capabilities and strategic management. Strategic Management Journal, 18(7), 509-533. Doi: 10.1002/(SICI)1097-0266(199708)18:7<509::AIDSMJ882>3.0.CO;2-Z

Vergara, S. C. (2000). Projetos e relatórios de pesquisa em administração. São Paulo: Atlas.

Wack, P. (1985). Cenários: atravessando as torrente. Harvard Business Review, Boston.

Wernerfelt, B. (1984). A resource-based view of the firm. Strategic Management Journal. v. 5, 171-180. Doi: $10.1002 / \mathrm{smj} .4250050207$

Recebido: 06/03/2012

Aprovado: 04/05/2012

Revista Ibero-Americana de Estratégia - RIAE, São Paulo, v. 11, n. 2, p. 91-119, mai./ago. 2012. 